\title{
HOW THE MARKET BECAME SOCIALIZED AND THE SOCIAL MISSION MARKETIZED
}

Review of Paul-Brian McInerney's From Social Movement to Moral Market: How the Circuit Riders Sparked an IT Revolution and Created a Technology Market (Stanford University Press 2014)

$\dot{A}_{K O S}$ BOCSKOR $^{1}$

Technological development and the presence of technological innovations and competences in the non-profit sector are vital for modern-day contemporary societies. As the benefits provided by modern technologies can significantly contribute to the success of enterprises and other initiatives, the availability of these technologies and having the competence to use them are increasingly in the forefront of interest. While bigger, profit-oriented businesses are generally able to finance the purchase of these products and services from the market, non-profit and grassroots organizations tend to lack the financial and/or human resources to fully exploit the opportunities they offer. Consequently, these organizations often fall behind compared to the public and business sector. As a response to this problem, alternative solutions - which range from searching for volunteers with special ICT competence to the foundation of non-profit support organizations - are followed. However, while many of these options can be useful and effective in certain situations, the demand for market-oriented professional services often arises.

In his fascinating book From Social Movement to Moral Market Paul-Brian McInerney presents the history and transformation of a social movement called Circuit Riders ${ }^{2}$ and their role in the emergence and establishment

1 Ákos Bocskor is Ph.D. student at the Corvinus University of Budapest; e-mail: akos.bocskor@ gmail.com

2 The name of the movement derives from the Methodist Circuit Riders of the $19^{\text {th }}$ century, when young Methodist preachers travelled around the United States to spread the new religion. The villages a preacher had to visit were plotted around a circuit, hence the name. 
of a moral market as an unintended consequence of their activity. This group of activists had one goal: supporting the cause of social justice and environmentalism by making available modern innovative technologies for non-profit and grassroots organizations. By doing so, they created demand for these technologies among actors from the sector. Consequently, more non-profit and grassroots organizations sought out advanced technological solutions from other providers as well, thus laying down the foundations of a new market sector.

The book might be interesting reading for any economist, sociologist or for any social scientist from another discipline who is open to bottom-up, actordriven theories of market creation and the process of institutionalization. It might also be a good choice for members of the wider public who are interested in better understanding the two-way interactions and interrelations which exist between market mechanisms and social movements. It could be especially useful to social movement activists, business managers and other stakeholders who are affected by these processes. Although, to my knowledge, there is no comparable initiative to Circuit Riders in Hungary, the social and market phenomena described in the book, as well as their theoretical and practical implications, are also relevant and interesting to Hungarian readers. There are several organizations that aid the non-profit sector in Hungary as well. For instance, the Nonprofit Információs és Oktató Központ Alapitvány [Non-profit Information and Educational Centre Foundation] provides complex ICT services to NGOs. ${ }^{3}$ However, the presence of profit-oriented "social enterprises" that blend social and market values is not as significant as it is in the United States. It is an interesting question whether a moral market similar to the American one will emerge in Hungary in the near future.

Paul-Brian McInerney is an assistant professor at the Department of Sociology at The University of Illinois at Chicago. His main research interests are economic and organizational sociology, sociology of technology, sociology of social movements, and sociological theory. ${ }^{4}$ Although this is the author's first published book, several previous articles and book chapters form the basis of the present work; for instance, his article The Nonprofit/ For-Profit Continuum: Theorizing the Dynamics of Mixed-Form Markets

3 For more details see www.niok.hu and www.civiltech.hu

4 All the information in this section, if not indicated otherwise, is based on McInerney's personal webpage and CV hosted on the University of Illinois at Chicago website. http://soc.uic.edu/ sociology/people/faculty/pbm 
(co-authored with Nicole P. Marwell ${ }^{5}$ ) which deals with the coexistence and dynamics between non-profit and for-profit organizations on the same market. Some other antecedents that deal with technological movements include the author's article Geeks for Good: Technology Evangelism and the Role of Circuit Riders in IT Adoption among Nonprofits, and a book chapter called Technology Movements and the Politics of Free and Open Source Software ${ }^{6}$.

Circuit Riders started as a small movement designed to help grassroots and non-profit organizations that focus on issues related to social justice and environmental protection. The aim was to enhance the digital capabilities of these organizations and thus channel new information technologies into the service of environmental and social good. In order to reach this goal, the Circuit Riders travelled all over the United States installing hardware and software and training staff in the use of new digital technologies, especially the Internet. However, as is common to many similar initiatives, the speedy success of Circuit Riders led to rapid growth of the organization and, as a result, the content and purpose of their enterprise gradually began to change. Due to the efficiency of their activity many non-profit organizations realized the importance of information technologies and, consequently, many of them began seeking out different technological solutions in the IT sector, outside the scope of the Circuit Riders. Therefore, raising the awareness of these organizations about the importance of digital technologies led them to seek out other market solutions as well. These developments also drew the attention of profit-oriented technology companies to the non-profit sector as a potential market.

Soon a competitor of Circuit Riders emerged, mixing market and social values to provide effective services for the non-profit sector. The new organization, called NPower, was a "social enterprise", adopting the methods used in business life to solve social problems. The application of modern technology and management practices in the designation, execution, and assessment of their activities made this organization much more similar to a typical business than Circuit Riders. However, their success was controversial as moral ambivalence caused tension between conflicting social and economic

5 Marwell, Nicole P. and McInerney, Paul-Brian. (2005) The Nonprofit/For-Profit Continuum: Theorizing the Dynamics of Mixed-Form Markets. Nonprofit and Voluntary Sector Quarterly. 34(1): 7-28.

6 McInerney, Paul-Brian. (2007). Geeks for Good: Technology Evangelism and the Role of Circuit Riders in IT Adoption among Nonprofits. Pp. 148-162 in Nonprofits and Technology: Emerging Research for Usable Knowledge. Michael Cortes and Kevin M. Rafter, (eds.), Chicago: Lyceum; McInerney, Paul-Brian. (2009). Technology Movements and the Politics of Free and Open Source Software. Science, Technology and Human Values. 34(2): 206-233. 
values. On the one hand, such hybrid companies are vulnerable to criticism from the perspective of social movements that may assume that they have lost the connection to their original goals. On the other hand, financial supporters, board members, and partners use market logic and values to assess the efficiency of such companies. Therefore balancing between the interests and expectations of different stakeholders consumes a considerable amount of the available resources.

Although the popularity of the services offered by the Circuit Riders declined, the social values that they embedded in the market remained. Their activity created demand for the implementation of modern technological solutions in the non-profit sector, while it also created demand for technological services for supporting social causes. Their work was completed by NPower and other similar technology providers who expanded the market to a wide range of types of non-profit organizations, not only to selected social justice and environmentalist movements. And although market values were followed, they did not come to dominate as the new non-profit technology assistant providers (NTAPs) always combined market values with social ones. Nevertheless, while many non-profit and grassroots organizations benefited from these changes which served to close the digital divide between themselves and the for-profit and governmental sectors, the marketization of technology assistance reinforced pre-existing inequalities within the nonprofit sector.

The book is divided into six chapters which follow up the history of the Circuit Riders and the expansion of their values from the birth of the movement to the creation of the new type of market. Each chapter focuses on one specific issue such as the birth of the movement (Chapter 1), the period of expansion (Chapter 2), the emergence of competition in the form of social enterprises (Chapter 3), the moral ambivalence these enterprises face (Chapter 4), and the different responses of the Circuit Riders to the new challenges (Chapter 5). In the last chapter McInerney comprehensively summarizes the most important social, market and transformational patterns outlined in the book, presents the current state of the Circuit Riders movement, offers new perspectives for the sociology of markets and movements for consideration and finally suggests practical implications for social movement activists and business managers.

Throughout the book the author provides a healthy balance of theoretical background literature, research data and amusing or appealing examples and quotations, thus ensuring a pleasant but at the same time thought-provoking experience for the reader. The thematic division of the material follows a logical arc as each chapter is organized around one central issue. Nevertheless, 
as chapters are interrelated, the most important ideas and observations recur from time to time.

McInerney bases his analysis on economic and organizational sociology, as well as on contemporary theories of collective behavior and social movements (he gives a brief but fairly comprehensive overview of the relevant literature in the Introduction). The empirical data come from longitudinal ethnography of the Circuit Riders technology movement. Throughout the book excerpts from interviews and the mailing list of the Circuit Riders are presented to demonstrate the points made or to introduce a more detailed analysis of a new theme. Additionally, excerpts from interviews with leaders or members of NPower and other NTAPs are also included. The author occasionally presents charts and different statistics to demonstrate his points; for instance, about the number of annual roundup attendees of the Circuit Riders, or the changes and distribution of the annual revenues of NPower. While both the qualitative and the quantitative data that are presented are attractive and suggestive, the persuasive power of both could be improved. Regarding the qualitative data (interview and mailing list excerpts), at some points the quantification of different ideas (for instance, presenting the frequency of different opinions expressed about the future of Circuit Riders on their mailing list) could justify the selection of certain quotations and the points that these quotations are often intended to support. As for the quantitative part, more statistics, tables, and diagrams could further enrich the analysis.

The author admits that many readers will be unfamiliar with the movement, even in America. He argues that this choice will allow many readers to approach the examples presented in the book with "fresh eyes". I believe this concept has its own merits, as well as some disadvantages. It seems quite plausible to assume that readers will have different attitudes towards organizations that are unknown to them, and will interpret these examples without the unavoidable biases and previous knowledge they may have regarding firms or movements that they are already familiar with. Nevertheless, although this more impersonal attitude shows clear advantages, emotional attachment and the ability to connect examples to readers' real-life experience would also be beneficial so as to more effectively maintain the interest and motivation of readers.

Although the title and the introduction of the book promise to describe the history of the Circuit Riders movement and its effect on the creation and transformation of the ICT market for non-profit organizations, the book actually does more than this. It starts from a description of the circumstances and historical conditions that led to the birth of the Circuit Riders movement and analyses its emergence and role in the creation of a new demand for 
ICT services. It then turns to NPower, the "social enterprise" that integrated both the social values promoted by the Circuit Riders and businessoriented approaches to market philosophy. The next step is an analysis of the establishment of other NTAPs based on the model provided by NPower and the emergence of the new "moral market" where economic and social interests are blended. The focus then turns to the conflicting economic and social interests and value systems that lead to moral ambivalence and multiple expectations from different stakeholders. The second half of the book mostly concentrates on the processes and dynamics of this moral market.

In his book McInerney demonstrates how the successful social movement of the Circuit Riders led to the implementation of their social values into one specific sector of the market. As a result of the movement's activity, a new moral market was created which blended social and economic values and gave way to the emergence of social firms that provide technological assistance to non-profit and grassroots organizations. The marketization of these services led to a decline in the Circuit Riders movement; however, their spirit has endured and has become an integral part of the new market. The author presents a profound analysis of the processes supporting it, using abundant research data. His bottom-up, actor-driven approach to analyzing market creation and institutionalization make the book insightful and scopewidening reading. Reading this book will be an enjoyable and stimulating experience for anyone interested in an analysis of the interactions and dynamics between economic markets and social movements that has a micro and meso-level focus. 